\title{
The Effect of Polypropylene and Steel Fibers on the Engineering Properties of Concrete
}

\author{
Dr. Tarig M. A. Ahmed ${ }^{1}$, Professor. Abid AbuTair ${ }^{2}$ \\ ${ }^{1,2}(\mathrm{PhD}$, BEng. London University, United Kingdom) \\ ${ }^{1}$ Fellow of the Institute for Learning and Teaching in Higher Education \\ ${ }^{1}$ Lecturer at Civil Engineering Department, Higher Colleges of Technology \\ AbuDhabi, UAE \\ tahmed@hct.ac.ae \\ ${ }^{2}$ British University \\ Dubai, UAE \\ abid.abu-tair@buid.ac.ae
}

\begin{abstract}
This paper presents results of an experimental investigation in which the effect of polypropylene, PP, and steel fibers, SF, on the mechanical properties of plain concrete was investigated. The effect of steel fibers only on the shear capacity of reinforced concrete beams was also studied. The results of the polypropylene and steel fibers were exerted with normal concrete; the studies show that the polypropylene reduces the mechanical properties of concrete whereas the steel fibers enhanced the mechanical properties of concrete as well as the shear capacity of the reinforced concrete beams.
\end{abstract}

Keywords: Mechanical properties, shear capacity, steel fibers, polypropylene, deflection

\section{Introduction}

An understanding of the effect of polypropylene, PP, and steel fibers, SF, on plain and reinforced concrete is necessary for design of varies concrete structures. Polypropylene fiber is a high monofilament which inhibits the formation of plastic shrinkage and plastic settlement cracking by providing an internal support system for concrete. This takes place when the concrete is beginning to harden and shrink due to volume changes from loss of water, most structures using polypropylene hold up well to earthquakes and fire. Steel fibers, SF, which is made from hard drawn steel wire, improves the cracks resistance ( or ductility ) capacity of the concrete, it also bridging across smaller crack forming after the application of load on the member, therefore preventing their widening into larger cracks

\section{Experimental Program}

\section{1 - Details of test Specimens}

The research described in this paper consists of two different parts. The first part deals with the effect of polypropylene, PP, and steel fibers, SF, on the mechanical properties of concrete. The following tests were carried out to study the latter;

1. compressive strength on $150 \times 150 \times 150 \mathrm{~mm}^{2}$ cubes ${ }^{[1]}$

2. Indirect tensile splitting on $100 \times 200 \mathrm{~mm}^{2}$ cylinders ${ }^{[2]}$

3. flexural strength, modulus of rupture, MoR , on 100x100x500 $\mathrm{mm}^{3}$ prisms ${ }^{[3]}$

4. static modulus of elasticity on $150 \times 300 \mathrm{~mm}^{2}$ cylinders ${ }^{[4]}$

5. water absorption on $150 \times 150 \times 150 \mathrm{~mm}^{3}$ cubes ${ }^{[5]}$

The effect of steel fibers on the shear capacity of reinforced concrete beams was studied in the second part of this investigation. Eight reinforced concrete beams of cross section $80 \mathrm{~mm} \times 130 \mathrm{~mm}$ and $1300 \mathrm{~mm}$ longer were cast with $12 \mathrm{~mm}$ diameter high tensile bars in the tension zone, the specimens were divided into 4 groups as shown below in Fig (1a-d) ${ }^{[6]}$

1. beam 1 : beam without links and poor anchorage of longitudinal reinforcement, figure 1a 
2. beam 2 : beam without links and good anchorage of longitudinal reinforcement figure $1 \mathrm{~b}$

3. beam 3 : beam with links and poor anchorage of longitudinal reinforcement, figure 1c

4. beam 4 : beam with links and good anchorage of longitudinal reinforcement, figure $1 \mathrm{~d}$

The poor anchorage detail was straight anchorage of $40 \mathrm{~mm}$, i.e. 3.5 times the bar diameter past the centre line of the support. $2.5 \mathrm{~mm}$ mild steel bars were used as shear reinforcement when links were provided. $6 \mathrm{~mm}$ diameter mild steel bars were provided as compression reinforcement in beams 3 and 4 . One beam from each of the previous groups were cast from steel fiber concrete, this was compared into identical beams cast from normal concrete. The two groups of beams were tested in similar way.

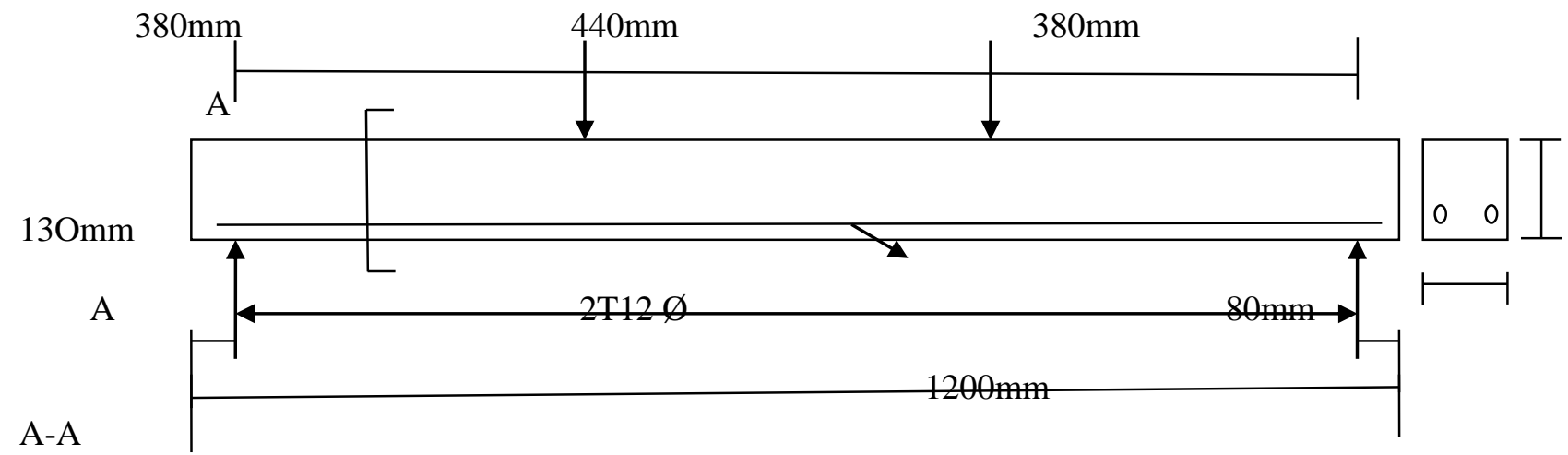
$50 \mathrm{~mm}$
$1300 \mathrm{~mm}$
$50 \mathrm{~mm}$

Fig. 1a: beam 1 - beam without links and poor anchorage of longitudinal reinforcement.

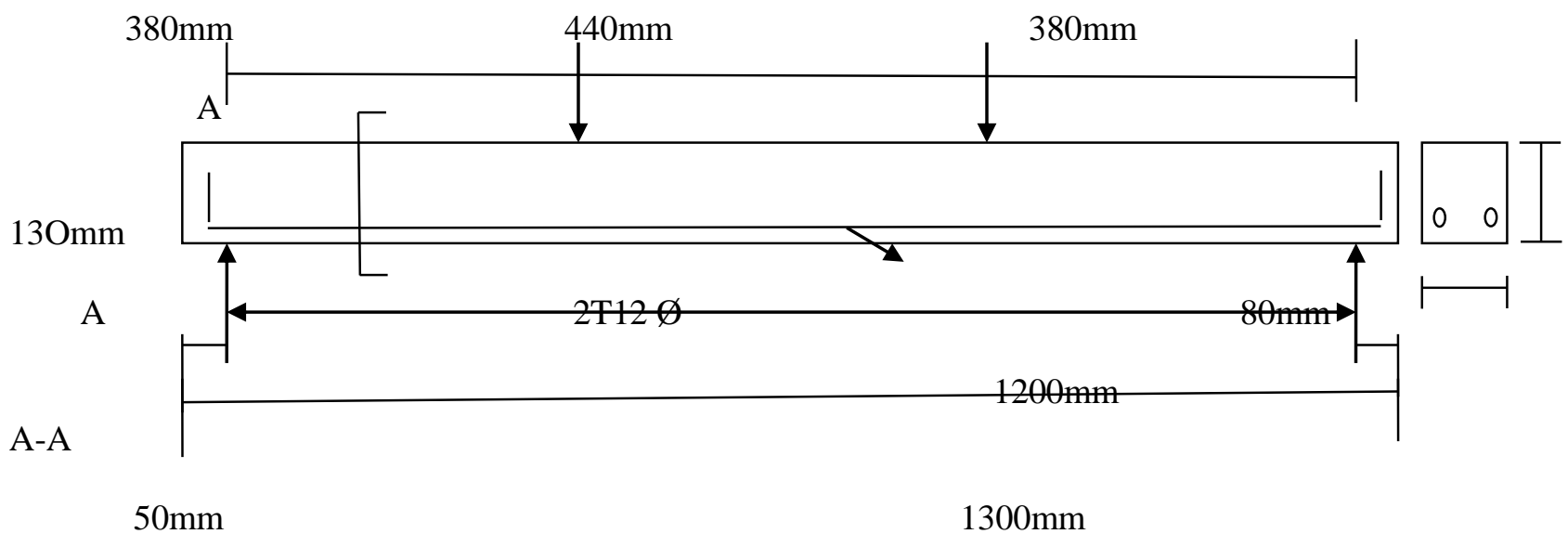

$50 \mathrm{~mm}$

Fig. 1b: beam 2 - beam without links and good anchorage of longitudinal reinforcement. 


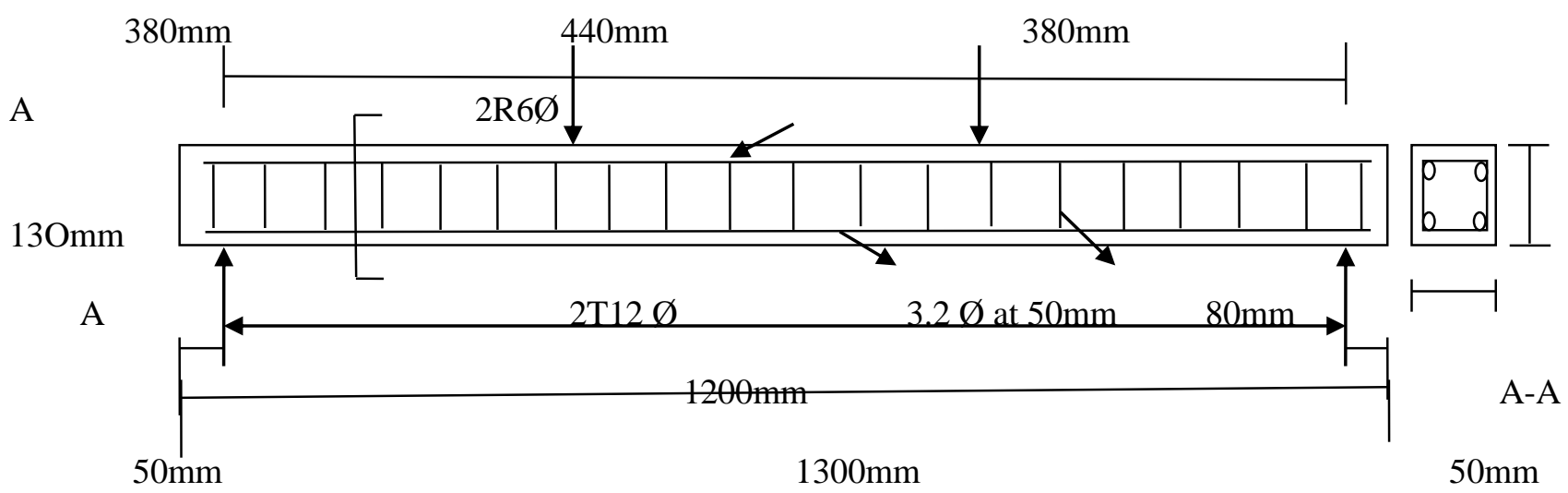

Fig. 1c: beam 3 - beam with links and poor anchorage of longitudinal reinforcement.

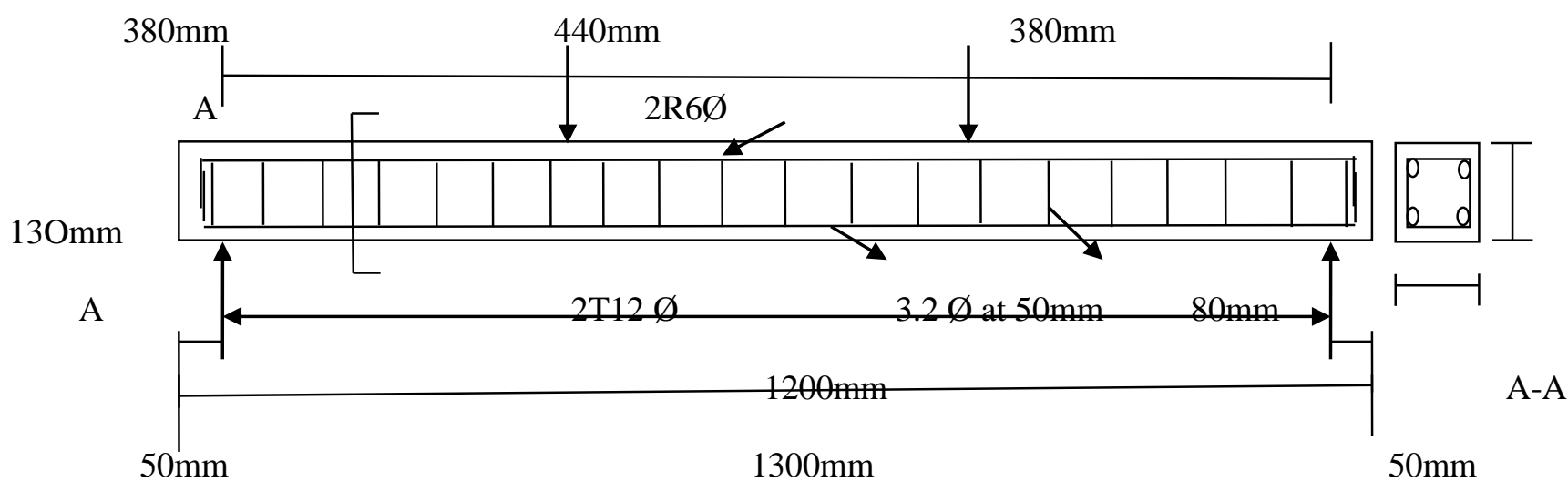

Fig. 1d: beam 4 - beam with links and good anchorage of longitudinal reinforcement.

\section{Concrete Mixes And Material Properties}

Four mixes were used to study the effect of polypropylene on the mechanical properties of plain concrete and another four mixes were used to investigate the effect of steel fiber on plain and reinforced concrete.

The contents of the polypropylene for mixes $1,2,3$ and 4 were $0 \mathrm{~kg} / \mathrm{m}^{3}, 0.91 \mathrm{~kg} / \mathrm{m}^{3}, 1.82 \mathrm{~kg} / \mathrm{m}^{3}$ and $2.73 \mathrm{~kg} / \mathrm{m}^{3}$ respectively, table $1 \mathrm{a}$. Mix 1 does not contain any polypropylene, $0 \mathrm{~kg} / \mathrm{m}^{3}$, was used as the control mix whereas mix $2,0.91 \mathrm{~kg} / \mathrm{m}^{3}$, was recommended by the manufacture. Four mixes were also used to study the effect of the steel fibers on the engineering properties of concrete, mixes $1,2,3$ and 4 contain $0 \mathrm{~kg} / \mathrm{m}^{3}, 10 \mathrm{~kg} / \mathrm{m}^{3}, 15$ $\mathrm{kg} / \mathrm{m}^{3}$ and $20 \mathrm{~kg} / \mathrm{m}^{3}$ of steel fibres respectively, table $1 \mathrm{~b}$. Mix $1,0 \mathrm{~kg} / \mathrm{m}^{3}$, was the control mix and mix 2,10 $\mathrm{kg} / \mathrm{m}^{3}$, was also recommended by the manufacturer.

Table 1a also shows the mix proportion of the concrete mix used for the test described in the previous paragraph, it contains $400 \mathrm{~kg} / \mathrm{m}^{3}$ of cement and w/c ratio of 0.5 was used. The same mix properties, table $1 \mathrm{~b}$, were used to study the effect of steel fiber on the shear capacity of reinforced concrete beams. The steel fiber content was $20 \mathrm{~kg} / \mathrm{m}^{3}$, identical to mix 4 which it was used to study the mechanical properties of concrete. 
Table 1a: Polypropylene mix proportions for mixes 1 (control), 2, 3 and 4.

\begin{tabular}{|c|c|c|c|}
\hline Ingredients & Source & Unit & Weight $\mathrm{m}^{3}$ \\
\hline OP Cement & UCC & $\mathrm{Kg}$ & 400 \\
\hline Water & MUN & Ltr & 700 \\
\hline $20 \mathrm{~mm}$ aggregate & RAK & $\mathrm{Kg}$ & 330 \\
\hline $10 \mathrm{~mm}$ aggregate & $\mathrm{RAK}$ & $\mathrm{Kg}$ & 515 \\
\hline $5 \mathrm{~mm}$ aggregate & $\mathrm{RAK}$ & $\mathrm{Kg}$ & 295 \\
\hline Sand - Fine & $\mathrm{RAK}$ & $\mathrm{Kg}$ & $0.0,0.91,1.82$ or 2.73 \\
\hline $\begin{array}{c}\text { Polypropylene } \\
\text { (Mixes 1,2,3 and 4) }\end{array}$ & Dramix & $\mathrm{Kg}$ & \\
\hline
\end{tabular}

Table 1b: Steel fibers mix proportions for mixes 1 (Control), 2, 3 and 4.

\begin{tabular}{|c|c|c|c|}
\hline Ingredients & Source & Unit & Weight $\mathrm{m}^{3}$ \\
\hline OP Cement & UCC & $\mathrm{kg}$ & 400 \\
\hline Water & MUN & $\mathrm{Ltr}$ & 200 \\
\hline $20 \mathrm{~mm}$ aggregate & RAK & $\mathrm{Kg}$ & 300 \\
\hline $10 \mathrm{~mm}$ aggregate & RAK & $\mathrm{Kg}$ & 515 \\
\hline $5 \mathrm{~mm}$ aggregate & RAK & $\mathrm{Kg}$ & 295 \\
\hline Sand $-\mathrm{F}$ & RAK & $\mathrm{Kg}$ & $0,10,15$ and 20 \\
\hline $\begin{array}{c}\text { Steel Fibers } \\
(\text { Mixes } 1,2,3 \text { and 4) }\end{array}$ & Dramix & $\mathrm{Kg}$ & \\
\hline
\end{tabular}

Polypropylene fibers are available as monofilament $12 \mathrm{~mm}$ in length for concrete use and $6 \mathrm{~mm}$ in length for plaster and mortar. The former was used in this investigation. The advantages of using polypropylene in concrete are;

a. Inhibits the formation of small cracks which can occur through plastic shrinkage, premature drying and early thermal changes

b. replaces anti cracks wire mesh

c. improves concrete durability and finishes characteristics

d. increase impact and abrasion resistance

e. impervious to alkali attack 
Typical content of polypropylene is shown in table 1c.

Table 1c: Typical content of Polypropylene.

\begin{tabular}{|c|c|}
\hline \multicolumn{2}{|c|}{ Typical content of polypropylene } \\
\hline Specific gravity & $0.91 \mathrm{gm} / \mathrm{cm}^{3}$ \\
\hline Alkali, sulphat and chloride content & nil \\
\hline Fiber thickness & 18 micron \\
\hline
\end{tabular}

Steel fibers concrete is more durable than plain concrete made from the same mix design. The fiber within the alkaline environment of the concrete are protected from corrosion, the aspect ratio (length/diameter $=\mathrm{L} / \mathrm{d}$ ) of the fibers has a major effect on workability. Three different steel fibers with different $\mathrm{L} / \mathrm{d}$ ratios of 45, 65 and 80 are available for basic requirements, quality control and minimum performance respectively. The latter was used for this investigation. These glued fibers offer the best in term of ductility, energy absorption and crack control.

\section{Manufacture Of The Specimens:}

The samples used to study the effect of polypropylene and steel fibers on the mechanical properties of concrete were cast in steel moulds; whereas the beams used to investigate the effect of steel fiber on the shear capacity of concrete were cast in timber moulds. The samples were vibrated externally using a table vibrator. After trowelling the concrete surface smooth, the beams were stored under polythene sheets. All the specimens were unmoulded after one day and then cured for 28 days in water tank at $20^{\circ} \mathrm{C}$ and $100 \%$ relative humidity. The tests were carried out within 1 hour of removal of the samples from the conditioning tanks.

\section{Apparatus And Test Procedure:}

The samples for investigating the mechanical properties of polypropylene concrete and steel fiber reinforced concrete were tested in a $3000 \mathrm{kN}$ controlled compression machine. The rate of loading was $0.3 \mathrm{~N} /\left(\mathrm{mm}^{2} . \mathrm{s}\right)^{[7]}$, all the specimens were seated directly on the rigid bed of the machine.

For testing the shear capacity of steel fibres concrete beams, the load was applied to the 8 beams using a $150 \mathrm{kN}$ hydromantic jack, giving a constant moment zone of $440 \mathrm{~mm}$ and shear span to effective depth ratio of 3.59. The supports were $50 \mathrm{~mm}$ from the ends of the beams, giving anchorage of 3.5 and 8.5 times the bar diameter for poor and good anchorage respectively, as shown in figure 1.

\section{Test results and discussion}

The static tests conducted to investigate the effect of both polypropylene and steel fiber on the mechanical properties of plain concrete are shown in table 2, whereas the results of the effect of steel fiber, only, on the shear capacity of reinforced concrete beams are shown in tables 3. 
Table 2: The effect of Polypropylene and steel fiber on the mechanical properties of concrete.

\begin{tabular}{|c|c|c|c|c|c|c|c|c|}
\hline \multirow[b]{2}{*}{$\begin{array}{l}\text { Properties of } \\
\text { Concrete }\end{array}$} & \multicolumn{4}{|c|}{ Steel Fiber } & \multicolumn{4}{|c|}{ Micro Polypropylene Fiber } \\
\hline & $\begin{array}{l}\text { Mix 1 - } \\
\text { Control } \\
\left(0 \mathrm{~kg} / \mathrm{m}^{3}\right)\end{array}$ & $\begin{array}{c}\operatorname{Mix} 2 \\
\left(10 \mathrm{~kg} / \mathrm{m}^{3}\right)\end{array}$ & $\begin{array}{c}\text { Mix } 3 \\
\left(\begin{array}{c}15 \mathrm{~kg} / \mathrm{m} \\
3\end{array}\right)\end{array}$ & $\begin{array}{c}\text { Mix } 4 \\
\left(\begin{array}{c}20 \mathrm{~kg} / \mathrm{m} \\
3\end{array}\right)\end{array}$ & $\begin{array}{l}\text { Mix } 1 \text { - } \\
\text { Control } \\
\left(0 \mathrm{~kg} / \mathrm{m}^{3}\right)\end{array}$ & $\begin{array}{c}\text { Mix } 2 \\
(0.91 \mathrm{~kg} / \\
\left.\mathrm{m}^{3}\right)\end{array}$ & $\begin{array}{c}\text { Mix 3 } \\
(1.82 k g / \\
\left.\text { m }^{3}\right)\end{array}$ & $\begin{array}{c}\text { Mix } 4 \\
(2.73 k g / \\
\left.\mathrm{m}^{3}\right)\end{array}$ \\
\hline $\begin{array}{c}\text { Cube } \\
\text { Compressive }\end{array}$ & & & & & & & & \\
\hline $\begin{array}{l}\text { Strength } \\
\left(\mathbf{N} / \mathbf{m m}^{2}\right)\end{array}$ & 52.58 & 58.04 & 58.32 & 58.34 & 44.78 & 43.70 & 39.03 & 37.57 \\
\hline $\begin{array}{c}\text { Cylinder } \\
\text { Compressive } \\
\text { Strength } \\
\left(\mathbf{N} / \mathbf{m m}^{2}\right)\end{array}$ & 21.44 & 27.52 & 29.32 & 29.67 & 30.98 & 26.74 & 24.98 & 21.97 \\
\hline Indirect Tensile & & & & & & & & \\
\hline Test $\left(\mathbf{N} / \mathbf{m m}^{2}\right)$ & 6.64 & 5.69 & 5.46 & 5.43 & 5.13 & 4.79 & 4.43 & 3.77 \\
\hline $\begin{array}{l}\text { Modulus of } \\
\text { Rupture } \\
\left(\mathbf{N} / \mathbf{m m}^{2}\right)\end{array}$ & 12.35 & 12.75 & 12.80 & 13.25 & 6.32 & 6.29 & 6.21 & 6.17 \\
\hline $\begin{array}{c}\text { Modulus of } \\
\text { Elasticity } \\
\left(\mathbf{N} / \mathbf{m m}^{2}\right)\end{array}$ & 42.27 & 39.63 & 35.23 & 22.12 & 42.27 & 28.82 & 27.57 & 26.42 \\
\hline $\begin{array}{c}\text { Water } \\
\text { Absorption } \\
\text { (g) }\end{array}$ & 0.11 & 0.10 & 0.10 & 0.11 & 97 & 101 & 104 & 107 \\
\hline Slump (mm) & 140 & 140 & 145 & 140 & 115 & 100 & 70 & 50 \\
\hline
\end{tabular}


Table 3: The Effect of Steel Fiber on the static strength, shear capacity, of reinforced concrete beam.

\begin{tabular}{|c|c|c|c|c||}
\hline Beam Code No. & $\begin{array}{c}\text { Ultimate } \\
\text { Load }(\mathbf{k N})\end{array}$ & \multirow{2}{*}{ Gain } & $\begin{array}{c}\text { Design Load } \\
(\mathbf{k N})\end{array}$ & Static failure occurred at \\
\hline Control Beam 1 & $\mathbf{3 4 . 0}$ & & $\mathbf{3 0 . 0 0}$ & Shear Span \\
\hline Steel Fiber Beam 1 & $\mathbf{4 0 . 0}$ & $\mathbf{1 7 . 6 5 \%}$ & $\mathbf{3 0 . 0 0}$ & Shear Span \\
\hline Control Beam 2 & 40.0 & & $\mathbf{3 0 . 0 0}$ & Shear Span \\
\hline Steel Fiber Beam 2 & $\mathbf{4 6 . 0}$ & $\mathbf{1 5 . 0 0 \%}$ & $\mathbf{3 0 . 0 0}$ & Shear Span \\
\hline Control Beam 3 & $\mathbf{5 6 . 0}$ & & $\mathbf{3 0 . 0 0}$ & Shear Span \\
\hline Steel Fiber Beam 3 & $\mathbf{6 9 . 5}$ & $\mathbf{2 4 . 1 1 \%}$ & $\mathbf{3 0 . 0 0}$ & Shear Span \\
\hline Control Beam 4 & $\mathbf{6 0 . 0}$ & & $\mathbf{3 0 . 0 0}$ & Shear Span \\
\hline Steel Fiber Beam 4 & $\mathbf{7 1 . 0}$ & $\mathbf{1 8 . 3 3 \%}$ & $\mathbf{3 0 . 0 0}$ & Shear Span \\
\hline
\end{tabular}

Beam 1: Beam with no links and poor anchorage

Beam 2: Beam with no link and good anchorage

Beam 3: Beam with links and poor anchorage

Beam 4: Beam with links and good anchorage

\section{6-1 The results of the first part of the research which is the effect of different percentage of polypropylene and steel fibres on the engineering properties of concrete is discussed below}

\section{6-1-1 Compressive Strength}

The effect of different percentage of polypropylene and steel fibres on the compressive strength of concrete are shown in table 2 . The cube compressive strength of concrete with polypropylene decreases as the content $\left(\mathrm{kg} / \mathrm{m}^{3}\right)$ of polypropylene increases. The drop in compressive strength for mixes 2,3 and 4 are approximately $2.4 \%, 14.7 \%$ and $19.9 \%$ compared with the control mix $1-0 \mathrm{~kg} / \mathrm{m}^{3}$ of polypropylene fibres. The increase of polypropylene, PP, content slightly increases the absorption of water and therefore affects the process of hydration and in turn reduces the compressive strength of concrete. Water and polypropylene, are grossly dissimilar in polarity and the lack of affinity for one another ${ }^{[8]}$ which means that the permeability of water through PP is low. The polarity mismatch also applies between PP and concrete, and this is likely to cause poor wetting at the interface between the fibres and concrete, so it is quite clear that the dissimilar in polarity and the lack of affinity between water and polypropylene, PP, and also between the latter and concrete affected the hydration process of concrete and therefore affect the strength of concrete. This is also explain the small variation of water absorption and the drop in slump values of mixes 2, 3 and 4 of the polypropylene, PP, concrete, table 2 .

On the other hand the addition of steel fibres to the concrete increases the cube compressive strength. The increase of the content of steel fibres in mixes 2, 3 and 4 showed an increase in the compressive strength of concrete cube of $10.38 \%, 10.92 \%$ and 10.95 compared to the control mix, mix 1, respectively. The increase in compressive strength of steel fibres, SF, concrete cube could be due to the increase in interlocking between concrete and the steel fibres. Further-more the orientation of the steel fibres impede the propagation of the crack due to the load and therefore delay the ultimate failure. It can also be seen that the addition of steel fibres to concrete has no effect on water absorption and the slump value, table 2.

It is quite clear that the increase in the compressive strength of steel fibres concrete does not depend on the amount of steel fibres added to the mixes, therefore increasing the steel fibres volume from $0 \mathrm{~kg} / \mathrm{m}^{3}$ in mix 2 to 15 $\mathrm{kg} / \mathrm{m}^{3}$ in mix 3 and $20 \mathrm{~kg} / \mathrm{m}^{3}$ in mix 4 gave almost the same compressive strength values. The reasons are that there is no increase in the energy which extend the crack and debond the fibres in the matrix. 
The results of the cylinder compressive strength for both polypropylene, PP, and the steel fibres, SF, show similar trend to the cube compressive strength, table 2 .

\subsubsection{Tensile Strength of Concrete}

The effect of the polypropylene on the tensile strength of concrete is shown in table 2, the addition of the polypropylene, $\mathrm{PP}$, decreases both the indirect tensile strength and flexural strength, i.e. modulus of rupture. The reduction in the indirect tensile strength for mixes 2,3 and 4 are approximately $6.6 \%, 13.65 \%$ and $26.51 \%$ compared with the control, mix $1-0 \mathrm{~kg} / \mathrm{m}^{3}$, respectively. On the other hand the decrease in the flexure strength, MoR, for mixes 2, 3 and 4 are approximately $0.5 \%, 1.7 \%$ and $2.4 \%$ compared with the control mix $1-0 \mathrm{~kg} / \mathrm{m}^{3}$, respectively.

It is clear that the polypropylene, PP, reduces the absorption of water and therefore affects the process of hydration; this creates non uniform stress distribution which leads to crack. Once the latter has formed, it can propagate quickly through the section of the specimen and in turn reduces the tensile strength of concrete.

Table 2 clearly shows that the increase in the steel fibres content decreases the indirect tensile strength but increases the Flexure strength, MoR. The reduction in the indirect tensile strength for mixes 2, 3 and 4 are $14.20 \%, 17.67 \%$ and $18.05 \%$ compared with the control, mix $1-0 \mathrm{~kg} / \mathrm{m}^{3}$, respectively. On the other hand the increase in the flexure strength, MoR, for the same mixes are 3.24\%, 3.64\% and 7.29\% compared with the control mix $1-0 \mathrm{~kg} / \mathrm{m}^{3}$, respectively. This could be due to the fact that the steel fibres, which are randomly distributed, do not aligned in the direction of the tensile stress. Therefore, it is quite clear that the steel fibres have less effect on the flexural strength than the indirect tensile strength.

The limited tests reported by Nguyen Van Chanh ${ }^{[9]}$ and also by Jeflery R Roesler at al ${ }^{[10]}$ showed that the steel fibres and the polypropylene do little to enhance the static compressive and tensile strength of concrete. Information regarding the other engineering properties discussed in this research was not reported by them.

\subsubsection{Modulus of Elasticity, MoE:}

Table 2 shows that the moduli of elasticity of both the polypropylene concrete and steel fibres concrete decreases as the PP and SF were added to the mixes. The MoE of PP and SF decreases as the content of the PP and SF fibres were increase in the mixes. Table 2 shows that the addition of $0.91 \mathrm{~kg} / \mathrm{m} 3,1.82 \mathrm{~kg} / \mathrm{m} 3$ and 2.73 $\mathrm{kg} / \mathrm{m} 3$ of polypropylene fibres to the concrete mix 1, 2 and 3 decreases the MoE by $31.82 \%, 34.78 \%$ and $37.5 \%$ compared to the control mix, mix $1-0 \mathrm{~kg} / \mathrm{m} 3$ of polypropylene, respectively. On the other hand the addition of the steel fibres to mix 2, 3 and 4 also causes reduction in the modulus of elasticity of $6.25 \%, 16.65 \%$ and $47.67 \%$ compared with the control, mix $1-0 \mathrm{~kg} / \mathrm{m} 3$, respectively, figure 10 . The reduction in the moduli of elasticity of both the polypropylene concrete and the steel fibres concrete could be due to the fact that the moduli of elasticity, $\mathrm{MoE}$, of the polypropylene and the steel fibres are low compare to the MoE of the corresponding properties of the matrix [11].

\subsubsection{Mode of Failure}

Figure 1 shows the mode failure of SF concrete cylinder tested in compression. The control specimens failed suddenly and there were no visible cracks before failure. This type of explosive failure was not observed on specimen cast from the SF mixes 2, 3 and 4. Therefore, Steel fibres in concrete, SF, resist the sudden explosion. It is clear that the samples fail longitudinally and explosive failure did not take place. Similar failure mode was reported in cylinder tested in tension. The polypropylene, PP, has no effect on the failure mode of the concrete cylinders tested in compression or tension. The latter fail in the same way as the control cylinder. It is clear that the steel fibres increase the resistant of the concrete to sudden failure. 


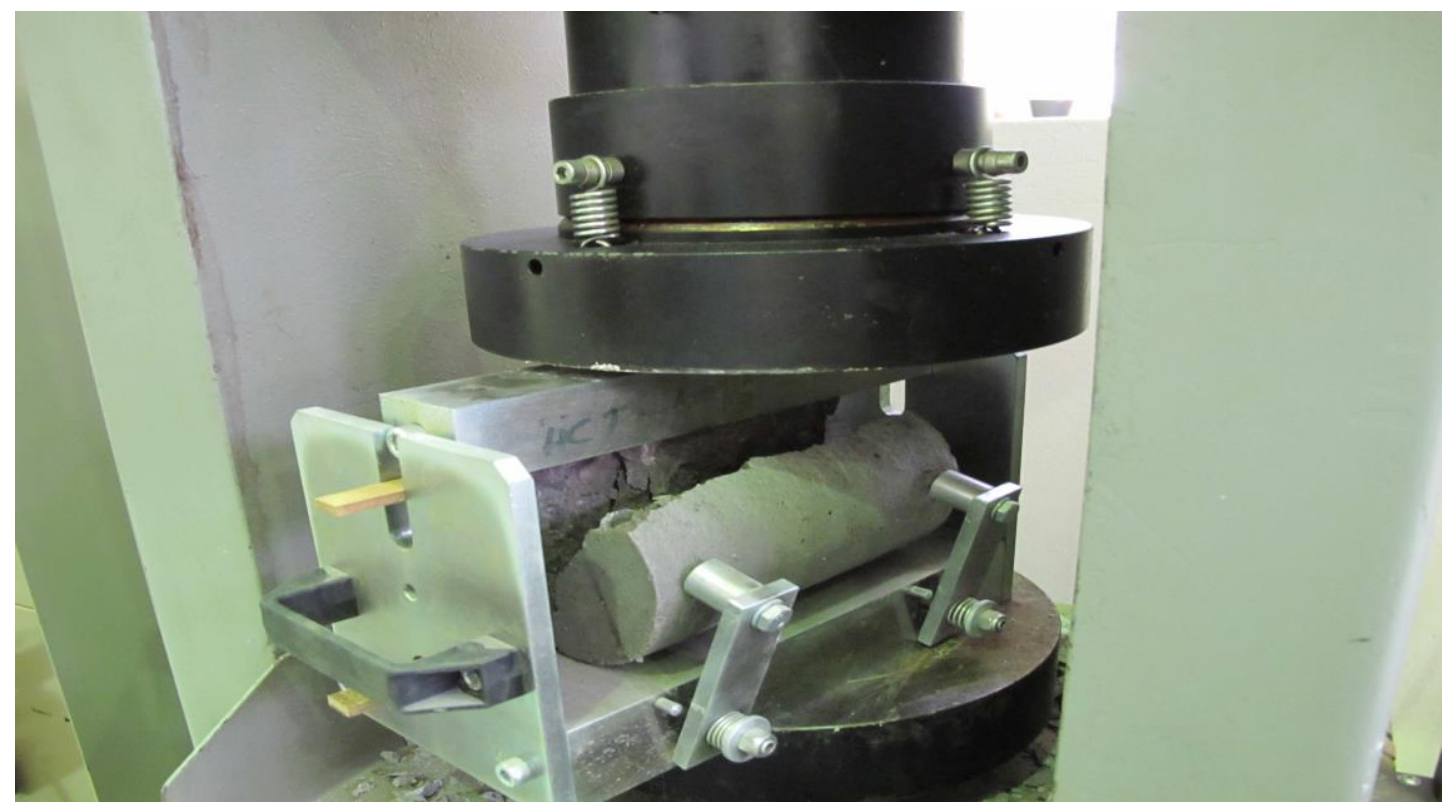

Fig. 1: Failure mode of Steel Fibres concrete cylinder tested in compression.

\section{2 - This section discusses the result of the second part of the research: The effect of steel fibres on the shear capacity of reinforced concrete beams}

Since the effect of polypropylene on concrete was not significant on the engineering properties of concrete, this part of the research concentrate on the effect of steel fibres on the shear capacity of reinforced concrete beams. Based on the findings from the experimental investigation, the following conclusions are drawn from table 3;

1- The steel fibres increase the shear capacity of reinforced concrete beams with or without shear links. The percentage increases in strength depends on whether the beam is singly reinforced or doubly reinforced.

2 - Table 3 also show that in the beams without links, the shear strength increased by $17.65 \%$ and $15 \%$ for beam 1 and beam 2 respectively, compared to the corresponding control specimens.

3- The steel fibres reinforced concrete beam, B2, and its control beam show an increase in the ultimate shear capacity than the steel fibres beam, B1, and it's control beam. Therefore the good end detailing increases the ultimate shear strength of the concrete beams.

4- Steel fibres reinforced concrete beams B3 and B4 show an increase in strength of $24.11 \%$ and $18.33 \%$ respectively compared to the corresponding control specimens.

5- In general the increase in the ultimate shear capacity of the steel fibres reinforced concrete beams is due to the fact that the shear forces were resisted by the increase in the compressive strength of concrete due to the presence of the steel fibres, as well as the transverse and longitudinal reinforcement. Kuang J.S et al ${ }^{[12]}$ and Bilal et al ${ }^{[13]}$ agreed that the addition of steel fibres in concrete leads to a substantial enhancement of shear carrying capacity of RC beam. The parameters tested by both researchers were different to the parameter tested in this research. 6 - The increase of the shear capacity of the SF reinforced concrete beams is also due to the fact that ${ }^{[14]}$;

- The random distribution of fibres throughout the volume of concrete at much closer space has led to distributed cracking with reduced crack size.

- The fibres also increase the first-crack tensile strength and ultimate tensile strength of the concrete.

- The shear friction strength is increased by resistance to pull-out and by fibres bridging cracks. 
7 - The deflection of the Steel fibres reinforced concrete beams, figure 2, was less than that of the corresponding normal concrete beams prior to cracking. The SF beams showed slightly higher deflection at failure as they failed at higher loads. Thus, SF reinforced beams have adequate deformation capacity in spite of their failure mode. The increasing deflection rate just prior to failure for all the beams suggested that the steel was beginning to yield and the beams, therefore, had reached their maximum load capacity.

8 - It can be noted from figure 3 that the steel fibres reinforced concrete beams SF1 and SF2 show less steep shear crack direction compared to the shear crack of their conventional reinforced concrete beams $\mathrm{C} 1$ and $\mathrm{C} 2$. The presence of the steel fibres, compression reinforcement and links in the steel fibres reinforced concrete beams SF3 and SF4 increases the compressive strength of the concrete and therefore causes steep shear crack direction compared to their control beams C3 and C4 respectively. Typical shear failure was recorded for all the beams; therefore it is clear that the increase in the shear capacity of the SF reinforced concrete beams did not alter or prevent the diagonal tension failure of the beams.

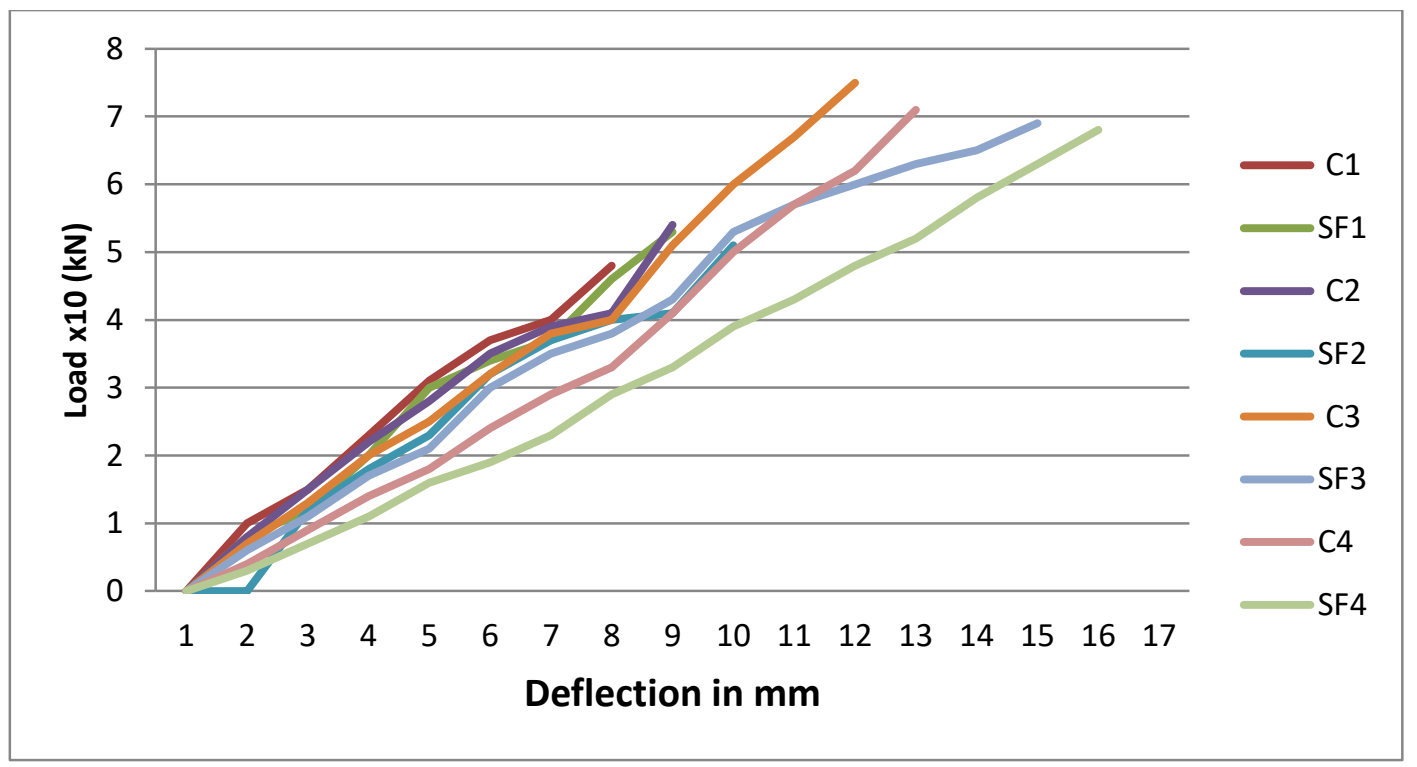

Fig. 2: Deflection of Steel Fibres Beams SF1, SF2, SF3, SF4 and their corresponding control against Load. 


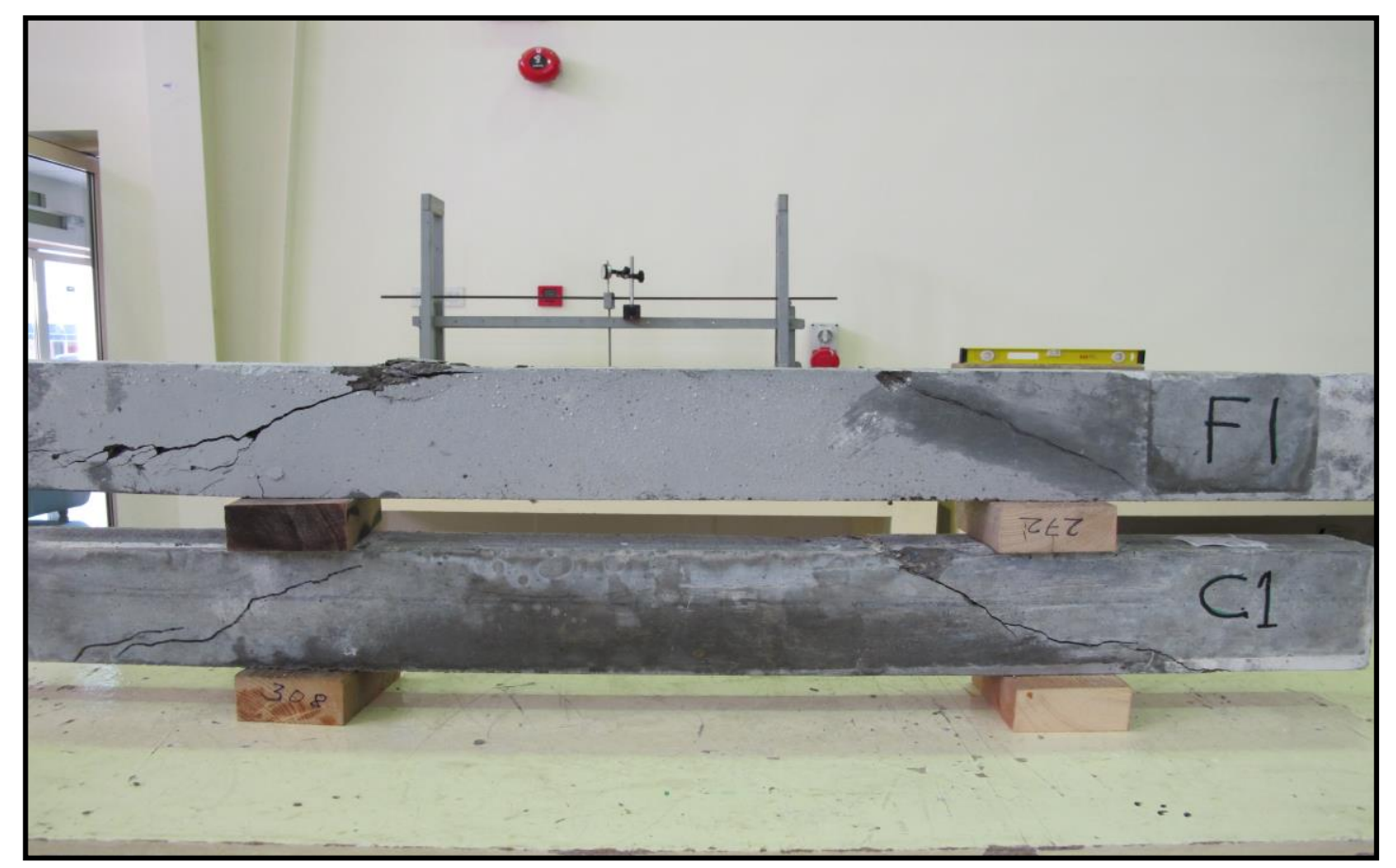

Fig. 3: Shear failure mode under static load, for steel fibres, SF1, and control beam, C1.

\section{Conclusions}

Based on the analysis of the test in the previous sections, the following conclusions are deduced;

1 - The addition of polypropylene slightly increases the water absorption but decreases the mechanical properties of concrete such as; cube compressive strength, cylinder compressive strength, indirect tensile strength, modulus of rupture, modulus of elasticity and the slump values. This could be due to the dissimilar in polarity and the lack of affinity between the PP and water. These lower the permeability of water and therefore affect the process of hydration which it leads to reduction in ultimate strength. On the other hand the steel fibres increase the cube compressive strength, cylinders compressive strength and the modulus of rupture of concrete but it decreases the indirect tensile strength and modulus of elasticity of concrete. This is due to the increase in interlocking between concrete and steel fibres and also the orientation of the steel fibres impede the propagation of the crack due to the load and therefore delay the ultimate failure. The water absorption and slump values of the SF concrete remain unchanged.

2 - The steel fibres in reinforced concrete beams enhance the shear capacity of singly or doubly reinforced concrete beams with or without good anchorage. The increase in shear strength, due to steal fibres, in beams with links was slightly greater at $18 \%$ regardless of the quality of the end anchorage of the main reinforcement compared to the control beams. The increase of the shear capacity of the SF concrete beams is due to the fact that the random distribution of fibres throughout the volume of concrete at much closer space has led to distributed cracking with reduced crack size. The fibres also increase the first-crack tensile strength and ultimate tensile strength of the concrete. The increase in shear capacity of the SF concrete beams can also be explained by the fact that the shear friction strength is increased by resistance to pull-out and by fibres bridging cracks. All the control and SF reinforced concrete beams failed in shear.

3 - The Steel fibres reinforced concrete beams tested in shear showed lower deflection than their corresponding normal concrete beams prior to cracking. Thus, SF reinforced beams have adequate deformation capacity in spite of their failure mode. The increase in deflection rate just prior to failure for all the beams suggested that the steel was beginning to yield and the beams, therefore, had reached their maximum load capacity. 
4 - A combination of vertical stirrup and randomly distributed steel fibres reinforcement in the matrix enhance the diagonal tension capacity of the concrete beams.

\section{Acknowledgment}

The author would like to thank Transgulf Ready Mix, AbuDhabi -UAE, for their help in preparing the sample used in this investigation. The author would also like to acknowledge support for this project from the technicians at the Higher Collages of Technology AbuDhabi Men's Collage, Civil Engineering Department AbuDhabi, United Arab Emirates.

\section{References:}

[1] BSEN 12390-3: Testing hardened concrete - Part 3: Method of determination of Compressive strength of cubes, 2000.

[2] BSEN1230-6: Testing hardened concrete - Part 6: Method of determination of tensile splitting strength: Making test cylinders from fresh concrete, 2000.

[3] BSEN 12390-5: Testing hardened concrete - Part 5: Method of determination of flexural strength, 2000.

[4] BS 1881: Testing Concrete Part 121 - Method of determination of static modulus of elasticity in compression. British Standard Institute London 1985.

[5] BS 1881: Testing Concrete Part 122 - Method of determination of water absorption. British Standard Institute London 1985.

[6] AHMED T.M.A et al "The static and fatigue strength of R.C beams affected by ASR " ACI materials Journal. Volume 95, no 4, July - August 1998, title no. 95.

[7] BS 8110: Part 1; 1985 " structural use of concrete" British Standard Institute London 1985.

[8] Khoury G.A and willoughby , B " polypropylene fibres in heated concrete :part1 : molecular structure and material behaviour" magazine of concrete research ,2008.60.no2,125-136.

[9] Chanh Nguyen Van "Steel Fibre Concrete" Proceedings of JSCE - VIFCEA Joint Seminar on Concrete Engineering in Vietnam, pp 108 - 116. December 8th - 9th, 2005 Ho Chi Minh University of Technology.

[10] JETTERY R. Roesler " effect of synthetic fibres on structural behaviour of concrete slabs on ground " ACI material journal V 103, N01, journey -February 2006 page 3-10.

[11] Brooks J. J and Neville A.M. "Concrete Technology". Longman scientific and technical 1994.

[12] Kuang J. S. and Baczkowski B. J. "Steel-fibres-reinforced concrete coupling beams subjected to monotonic loading" Magazine of concrete research, 2009 - 61 - No. 1. February, 35-41.

[13] Bilal S. Hamad and Charbel D. Bou Abs "Effect of fibres reinforced Polymer Confinement on Bond Strength of Hooked Bars in High-Strength Concrete" ACI Structural journal V 106, N06, NovemberDecember 2009. Page 831-839.

[14] State-of-the-Art Report on Fibre Reinforced Concrete. ACI Committee 544, 1R-96. 2002. 